\title{
Role of lipid peroxidation and antioxidant enzymes in omega 3 fatty acids induced suppression of breast cancer xenograft growth in mice

\author{
W Elaine Hardman*1, Jesus Munoz $\mathrm{Jr}^{2}$ and Ivan L Cameron ${ }^{2}$
}

Address: ${ }^{1}$ Pennington Biomedical Research Center, Louisiana State University, 6400 Perkins Road, Baton Rouge LA 70808, USA and ${ }^{2}$ The University of Texas Health Science Center at San Antonio, Dept of Cellular and Structural Biology, 7703 Floyd Curl Dr., USA, San Antonio, TX 78229-3900, USA

E-mail: W Elaine Hardman* - hardmawe@pbrc.edu; Jesus Munoz - cameron@uthscsa.edu; Ivan L Cameron - cameron@uthscsa.edu

${ }^{*}$ Corresponding author

Published: 17 July 2002

Cancer Cell International 2002, 2:10

This article is available from: http://www.cancerci.com/content/2///10

(C) 2002 Hardman et al; licensee BioMed Central Ltd. This article is published in Open Access: verbatim copying and redistribution of this article are permitted in all media for any non-commercial purpose, provided this notice is preserved along with the article's original URL.
Received: 23 January 2002

Accepted: 17 July 2002

\begin{abstract}
Background: Supplementing mice with high levels of dietary n-3 polyunsaturated fatty acids (PUFAs) increases the n-3 PUFAs in cell membranes, increases the susceptibility of the cells for lipid peroxidation (LPO) and decreases the growth rate of mammary and other tumors. However, the results of an earlier study indicated that a factor in addition to LPO was involved in the reduction in tumor growth in n-3 PUFAs fed mice. Athymic mice bearing MDA-MB-23I human breast carcinoma xenografts, were fed fish oil concentrate (FOC) or control diets, with and without supplemental Vitamin E (2000 IU / kg diet) and were sacrificed both before and after doxorubicin (DOX) treatment to evaluate factors involved in tumor growth suppression.

Results: Prior to DOX, basal LPO in the tumor of 3\% FOC fed mice was slightly higher than in the control fed mice and was decreased in mice consuming FOC with vitamin E. Vitamin $E$ suppressed the DOX induced increase in LPO in the tumors of control mice, however, vitamin E was not sufficient to suppress a DOX induced increase in LPO in the tumors of FOC fed mice. The mean growth rate of tumors of FOC fed mice was significantly less than the mean growth rate of the tumors of control mice. Multiple regression analyses indicated that suppression of glutathione peroxidase (GPX) activity by FOC prior to DOX therapy was more important than increased LPO as an explanation of tumor growth suppression. Tumor induced cachexia was decreased in mice consuming FOC.
\end{abstract}

Conclusions: It appears that the increased sensitivity to DOX was related to an FOC induced reduction in GPX activity. FOC reduced tumor induced cachexia.

\section{Background}

The results of cell culture and animal studies have shown that omega 3 polyunsaturated fatty acids (n-3 PUFAs) selectively killed cancer cells in vitro [1]. Furthermore, n-3 PUFAs incorporated into animal diets have reduced tumor growth rates in vivo [2-4]. The prevailing hypothesis for the reduction in tumor cell growth, in vitro or in vivo, by supplementing the diet with high levels of n-3 PUFAs has been that the incorporation of n-3 PUFAs into cell membranes of the tumor cells increased the susceptibility of the cells for lipid peroxidation and that the products of lipid peroxidation subsequently accumulated to cytostatic or cytotoxic levels $[2,5-7]$. It has also been reported that supplementing the diet of cancer xenograft bearing mice 
with n-3 PUFAs could increase the efficacy of edelfosine [8], doxorubicin [9], mitomycin [10], cyclophosphomide and 5-fluorouracil [11] or irinotecan [12] against the tumor. Since causing oxidative damage is one of the mechanisms of action of many of these drugs [13], the increased efficacy of the drug has been attributed to increasing the susceptibility of tumor cell membranes to lipid peroxidation.

However, the results of one of our early studies indicated that some factor in addition to lipid peroxidation was involved in the reduction in xenograft growth in fish oil fed mice [8]. A clue as to this factor(s) was found in the report by Vankatraman et al. that antioxidant enzyme activity in the liver was altered following long term consumption of n-3 PUFAs [14]. We reasoned that alteration of antioxidant enzyme activity in the tumor by consumption of n-3 PUFAs prior to chemotherapy treatment could increase oxidative stress within the tumor, perhaps resulting an enhanced sensitivity to oxidative stress induced by doxorubicin (DOX).

In this study, we wanted to test the hypothesis that there are changes in the breast cancer xenografts of FOC fed mice that sensitize the tumor to oxidative stress. MDA-MB 231 human breast cancer bearing athymic mice were fed fish oil concentrate (FOC) or control diets, with and without supplemental vitamin $\mathrm{E}$ and were euthanized both before and after DOX treatment to test this hypothesis. DOX was used to induce oxidative stress, supplemental vitamin E was used to quench oxidative stress. An important aspect of the present study was that the n-3 PUFAs dietary supplement be fed to mice at a level that humans could readily consume. This level was based on calculation of calories contributed by the oil as a fraction of the total caloric content of the diet. A product containing more than $65 \%$ omega 3 ethyl esters was used to increase the amount of long chain n-3 PUFAs contained in a small quantity of the n-3 PUFAs supplement. A high amount of $\alpha$-tocopherol, (vitamin E, $2000 \mathrm{IU} / \mathrm{kg}$ diet) was added to the diet of some mice to suppress lipid peroxidation in tissues.

\section{Results \\ Fatty acid composition}

The fatty acid compositions of the microsomal and mitochondrial membrane fractions of liver, colon and MDAMB 231 human breast tumor were analyzed by gas chromatography. The individual percent compositions for $\alpha$ linolenic, eicosapentaenoic and docosahexaenoic acids were summed to estimate the fraction of n-3 fatty acids. The individual percent compositions for linoleic and arachidonic acids were summed to estimate the fraction of n6 fatty acids. The ratios of the n- 3 to n- 6 fatty acids in each tissue and subcellular fraction were subjected to statistical analyses. A two way ANOVA revealed that the n-3 to n- 6 ratio (Table 1) was significantly higher in mice that consumed FOC than in mice that consumed corn oil (CO) indicating that n-3 fatty acids were incorporated in cellular membranes when FOC was provided in the diet of the diet. Supplemental Vitamin E in the diet did not effect the ratio of n-3 to n-6 fatty acids.

\section{Antioxidant enzyme activity}

To determine the effect of consumption of FOC on endogenous antioxidant enzyme activity, the activities of superoxide dismutase (SOD), catalase (CAT) and glutathione peroxidase (GPX) were determined in the liver, colon and tumor of mice that had consumed the diet for two weeks. As summarized in Table 2, two way ANOVA revealed that the activities of SOD, CAT and GPX were not significantly altered in the liver or colon due to the consumption of FOC or of supplemental Vitamin E for two weeks. However, GPX activity was significantly less in the tumors of mice that consumed FOC than in the tumors of mice that consumed CO and supplemental Vitamin E did not significantly alter GPX activity. Thus, the effect of consumption of FOC on GPX activity was different in the tumor than in the normal host liver or colon.

\section{Lipid peroxidation}

Lipid peroxidation was assayed in the livers, colons and tumors of mice sacrificed after two weeks consumption of each diet and after two weeks consumption of the diets and a single injection of DOX $24 \mathrm{~h}$ before sacrifice (Table 3 ). Three way, two way and one way ANOVA revealed that in the:

\section{I) liver and colon}

a) Lipid peroxidation was slightly suppressed by the addition of vitamin E to either diet, b) DOX treatment did not significantly increase lipid peroxidation.

\section{2) tumor}

a) Supplemental vitamin E prevented an FOC induced increase in basal lipid peroxidation, b) supplemental vitamin E prevented the DOX induced increase in lipid peroxidation in mice that consumed the corn oil diet but did NOT prevent a DOX induced increase in lipid peroxidation in mice that consumed the FOC diet.

\section{Tumor growth rates}

Figure 1 illustrates the mean growth rates of the tumors of each dietary group following DOX treatment. ANOVA revealed that the growth rates of the tumors of both groups that consumed FOC were significantly less than the mean growth rates of both of the groups of mice that consumed either $\mathrm{CO}$ diet. 

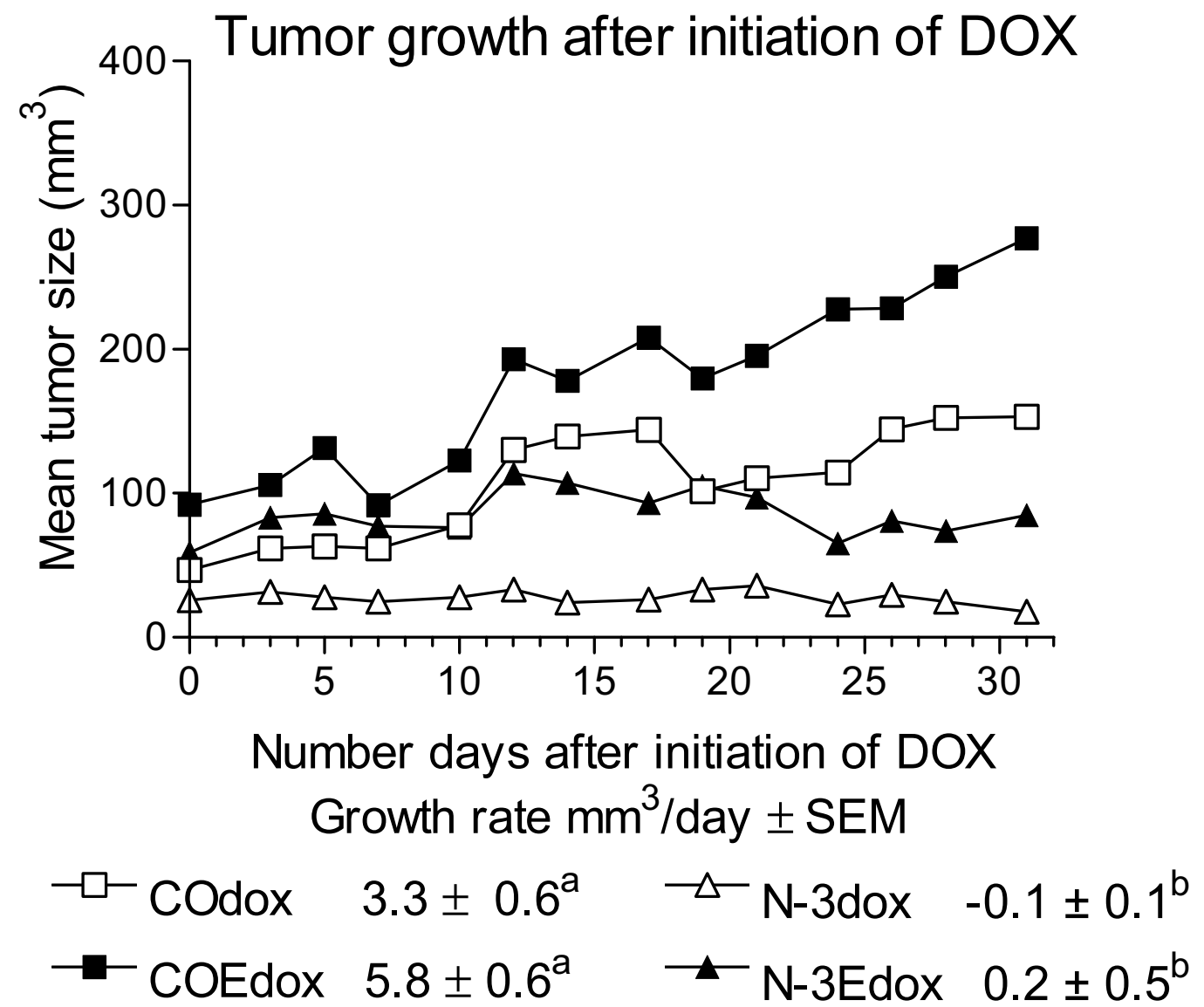

Figure I

Tumor growth after initiation of DOX treatment (see methods for dose and diets). Day 0 on the graph was the day of the first DOX injection. The mean \pm SE of the slope of each group $(n=4-8$ per group) is indicated. One-way ANOVA followed by an SNK multiple comparison test indicated that the slopes (tumor growth rates in $\mathrm{mm}^{3} / \mathrm{day}$ ) of groups which do not share a superscript were significantly $(p<0.05)$ different.

Table I: The ratio of n-3 to n-6 fatty acids in the microsomal or mitochondrial membranes of liver, colon or tumor in mice fed a diet containing either $5 \%$ corn oil (CO) or $3 \%$ fish oil concentrate (FOC) and $2 \%$ CO with or without 2000 IU/kg Vitamin E for two weeks. Two way ANOVA revealed that consumption of supplemental Vitamin $E$ did not effect the fatty acid composition thus ratios due to dietary fat are shown. Mean \pm SEM, (n).

\begin{tabular}{|c|c|c|c|c|}
\hline Tissue & Fraction & $5 \% \mathrm{CO}$ & $3 \% \mathrm{FOC} / 2 \% \mathrm{CO}^{\mathrm{a}}$ & Fold difference \\
\hline \multirow[t]{2}{*}{ Liver } & Microsomal & $0.06 \pm 0.02(8)$ & $1.1 \mathrm{I} \pm 0.18$ (7) & 18.5 \\
\hline & Mitochondrial & $0.09 \pm 0.02$ & $0.77 \pm 0.08(7)$ & 8.6 \\
\hline \multirow[t]{2}{*}{ Colon } & Microsomal & $0.18 \pm 0.09(8)$ & $0.62 \pm 0.15(7)$ & 3.4 \\
\hline & Mitochondrial & $0.24 \pm 0.09$ & $0.59 \pm 0.24(7)$ & 2.5 \\
\hline \multirow[t]{2}{*}{ Tumor } & Microsomal & $0.11 \pm 0.10$ & $1.15 \pm 0.10(7)$ & 10.5 \\
\hline & Mitochondrial & $0.59 \pm 0.57(8)$ & $1.32 \pm 0.37(7)$ & 2.2 \\
\hline
\end{tabular}

a The $n-3$ to $n-6$ ratio was significantly higher in every tissue fraction of mice that consumed the FOC diet than in mice that consumed the CO diet. 
Table 2: Activities (mean + SE) of superoxide dismutase (SOD, units/mg protein), catalase (CAT, $\mu \mathrm{mol} \mathrm{H}_{2} \mathrm{O}_{2}$ decomposed/min/mg protein) and glutathione peroxidase (GPX, $\mu \mathrm{mol} \beta$-NADP oxidized/g protein) in the tumors, livers and colon of groups of mice fed diets containing either $5 \%$ CO or $3 \%$ FOC and $2 \%$ CO with or without 2000 IU Vitamin E/kg diet for two weeks.

\begin{tabular}{|c|c|c|c|c|}
\hline Diet type & $n$ & SOD & GPX & CAT \\
\hline \multicolumn{5}{|c|}{ Tumor } \\
\hline $5 \% \mathrm{CO}$ & 3 & $10.0 \pm 3.2$ & $|3| \pm 24^{a}$ & $20 \pm 6$ \\
\hline $5 \% \mathrm{CO}+\mathrm{E}$ & 3 & $17.4 \pm 7.2$ & $118 \pm 17^{a}$ & $40 \pm 17$ \\
\hline $3 \%$ FOC & 4 & $9.0 \pm 2.3$ & $60 \pm 23^{a}$ & $28 \pm 7$ \\
\hline $3 \% \mathrm{FOC}+\mathrm{E}$ & 3 & $14.1 \pm 1.9$ & $13 \pm 9 b$ & $30 \pm 10$ \\
\hline \multicolumn{5}{|c|}{ Liver } \\
\hline $5 \% \mathrm{CO}$ & 3 & $214 \pm 44$ & $358 \pm 36$ & $531 \pm 28$ \\
\hline $5 \% \mathrm{CO}+\mathrm{E}$ & 3 & $159 \pm 16$ & $301 \pm 65$ & $535 \pm 12$ \\
\hline $3 \% \mathrm{FOC}$ & 4 & $156 \pm 39$ & $308 \pm 73$ & $579 \pm 22$ \\
\hline $3 \% \mathrm{FOC}+\mathrm{E}$ & 3 & $87 \pm 10$ & $331 \pm 96$ & $587 \pm 67$ \\
\hline \multicolumn{5}{|c|}{ Colon } \\
\hline $5 \% \mathrm{CO}$ & 3 & $4.8 \pm 0.4$ & $325 \pm 59$ & $28 \pm 13$ \\
\hline $5 \% \mathrm{CO}+\mathrm{E}$ & 3 & $11.5 \pm 1.5$ & $220 \pm 38$ & $35 \pm 14$ \\
\hline $3 \% \mathrm{FOC}$ & 4 & $2.2 \pm 0.6$ & $172 \pm 53$ & $21 \pm 5$ \\
\hline $3 \% \mathrm{FOC}+\mathrm{E}$ & 3 & $10.5 \pm 3.6$ & $199 \pm 42$ & $33 \pm 9$ \\
\hline
\end{tabular}

a One way ANOVA followed by an SNK multiple comparison test indicated that the mean GPX in the tumors of groups that share a superscript were not significantly different $(\mathrm{p}<0.05)$. There were no other significant differences.

Table 3: Thiobarbituric acid reactive substances (TBARS, nmols/mg protein, mean $\pm \mathrm{SE}$ ) in the tumors, livers and colons of groups of mice fed diets containing either $5 \%$ CO or $3 \%$ FOC and $2 \%$ CO with or without 2000 IU Vitamin E/kg diet for two weeks. Some mice were sacrificed $24 \mathrm{~h}$ after one injection of DOX ( $5 \mathrm{mg} / \mathrm{kg}$ body weight, i.v.).

\begin{tabular}{|c|c|c|c|c|}
\hline Diet type & $\mathrm{n}$ & TBARS before DOX & $\mathrm{n}$ & TBARS after DOX \\
\hline \multicolumn{5}{|c|}{ Tumor } \\
\hline $5 \% \mathrm{CO}$ & 4 & $0.59 \pm 0.30^{c d}$ & 3 & $0.79 \pm 0.12^{\mathrm{cd}}$ \\
\hline $5 \% \mathrm{CO}+\mathrm{E}$ & 5 & $0.53 \pm 0.05^{c d}$ & 4 & $0.59 \pm 0.2 \mathrm{Icd}$ \\
\hline $3 \% \mathrm{FOC}$ & 4 & $1.09 \pm 0.14 b c$ & 3 & $1.46 \pm 0.29 b$ \\
\hline $3 \% \mathrm{FOC}+\mathrm{E}$ & 3 & $0.38 \pm 0.15^{d}$ & 4 & $2.37 \pm 0.37^{a}$ \\
\hline \multicolumn{5}{|c|}{ Liver } \\
\hline $5 \% \mathrm{CO}$ & 4 & $1.09 \pm 0.38^{b}$ & 3 & $0.98 \pm 0.06^{b}$ \\
\hline $5 \% \mathrm{CO}+\mathrm{E}$ & 5 & $0.69 \pm 0.10^{b}$ & 5 & $0.7 \mathrm{I} \pm 0.09 \mathrm{~b}$ \\
\hline $3 \% \mathrm{FOC}$ & 4 & $1.77 \pm 0.19 \mathrm{a}$ & 4 & $1.99 \pm 0.3 \mathrm{I}^{\mathrm{a}}$ \\
\hline $3 \% \mathrm{FOC}+\mathrm{E}$ & 3 & $0.61 \pm 0.08^{b}$ & 4 & $0.60 \pm 0.08^{b}$ \\
\hline \multicolumn{5}{|c|}{ Colon } \\
\hline $5 \% \mathrm{CO}$ & 3 & $2.58 \pm 0.47^{a}$ & 3 & $1.21 \pm 0.57^{\mathrm{a}}$ \\
\hline $5 \% \mathrm{CO}+\mathrm{E}$ & 4 & $2.10 \pm 1.72^{\mathrm{a}}$ & 5 & $1.00 \pm 0.48^{\mathrm{a}}$ \\
\hline $3 \% \mathrm{FOC}$ & 4 & $3.40 \pm 1.13^{a}$ & 4 & $2.59 \pm 1.0 \mathrm{I}^{\mathrm{a}}$ \\
\hline $3 \% \mathrm{FOC}+\mathrm{E}$ & 3 & $2.27 \pm 1.22^{\mathrm{a}}$ & 5 & $2.35 \pm 0.77^{a}$ \\
\hline
\end{tabular}

a,b,c,d One way ANOVA followed by an SNK multiple comparison test indicated that within each tissue type the mean TBARS of each group that share a superscript were not significantly $(p<0.05)$ different. 
Table 4: Summary of forward multiple regression analyses between the measured independent variables: SOD, CAT and GPX activities in the tumor and the TBARS in the tumor as measured after two weeks on the diet but before DOX treatment or as measured $24 \mathrm{~h}$ after a single injection of DOX and the dependent variable, tumor growth rate during 5 weeks of DOC treatment.

\begin{tabular}{|c|c|c|c|}
\hline Variable entered into equation & Parameter estimate & $\begin{array}{c}\text { Partial } R^{2} \text { (Contribution each } \\
\text { variable) }\end{array}$ & $\begin{array}{c}\text { Cumulative } \mathrm{R}^{2} \text { (Cumulative con- } \\
\text { tribution) }\end{array}$ \\
\hline Intercept & -17.3 & & \\
\hline GPX & 0.138 & 0.78 & 0.78 \\
\hline TBARS after DOX & 6.50 & 0.19 & 0.97 \\
\hline
\end{tabular}

Table 5: Mean body weight change g/wk \pm SE (n) due to diet and to DOX treatment in mice bearing an MDA-MB-23 I human breast cancer xenograft.

\begin{tabular}{lcc}
\hline Diet type & Before DOX treatment Body weight change & After DOX treatment Body weight change \\
\hline & & $-0.42 \pm 0.12(6)$ \\
$5 \%$ CO & $0.19 \pm 0.15(15)$ & $-0.32 \pm 0.08(8)$ \\
$5 \%$ CO + E & $0.11 \pm 0.11(17)$ & $-0.32 \pm 0.08(6)$ \\
$3 \%$ FOC & $0.52 \pm 0.06(23)$ & $-0.40 \pm 0.08(4)$ \\
$3 \%$ FOC + E & $0.33 \pm 0.06(22)$ & $N S$ \\
Results of 2-way ANOVA & Sa & NS \\
Fat & NS & NS \\
Vit. E & NS & \\
Diet ${ }^{*}$ Vit. E & &
\end{tabular}

a The tumor bearing mice fed FOC gained significantly more body weight than tumor bearing mice fed CO before DOX treatment. There was no significant difference in body weight loss due to diet in mice given DOX treatment for five weeks.

\section{Multiple regression analyses}

Values for the means of SOD, CAT, GPX activities and TBARS from the tumors of groups of mice killed after two weeks on each diet with or without DOX treatment and the mean tumor growth rate of mice fed each diet and treated with DOX for five weeks were entered into a forward multiple regression analyses. Multiple regression analyses can address the question: What variable(s) present in the tumor prior to or after DOX treatment best correlates with the response of the tumor to DOX treatment? The results of the analyses (Table 4 ) revealed that GPX activity in the tumor prior to DOX treatment explained $78 \%$ of the variation in tumor growth rate (the correlation coefficient (r) between GPX activity in the tumor before DOX treatment and the tumor growth rate following DOX treatment was 0.88). Increased TBARS following DOX treatment added an additional 19\% explanation for the variation in tumor growth rate. Thus, $97 \%$ of the variation in tumor growth rate could be explained by the diet induced decrease in GPX activity and by increased lipid peroxidation in the tumor following DOX treatment.

\section{Body weight}

The mean body weight change of each group of tumor bearing mice following consumption of each diet for two weeks or following DOX treatment for five weeks was determined. Two way ANOVA (Table 5) revealed that addition of Vitamin $\mathrm{E}$ to the diet did not significantly effect body weight but that mice that consumed FOC prior to DOX treatment gained significantly more weight than did mice that consumed CO. Neither fat type nor Vitamin E supplementation significantly altered the change in body weight during five weeks of DOX treatment.

\section{Discussion}

The results of previous studies [2,5-8] indicated that peroxidation of highly polyunsaturated n-3 fatty acids, incorporated into cell membranes following their consumption, was likely to be the primary mechanism for tumor growth suppression following consumption of fish oil. However, we recently reported that cellular oxidative stress, as assayed by the ratio of glutathione peroxidase (GPX) to superoxide dismutase (SOD) activity, was higher in the MDA-MB 231 breast cancer xenograft of mice that were fed $3 \% \mathrm{w} / \mathrm{w}$ FOC with $2 \% \mathrm{w} / \mathrm{w}$ corn oil prior to and during 5 weeks of DOX treatment [15] than in the breast 
cancer xenografts of mice that were fed 5\% corn oil. If dietary antioxidants are constant, the antioxidative capacity of tissues depends on the levels of protective cellular antioxidants [16]. Since endogenous antioxidative enzymes can be altered by FOC consumption [14], we wondered if oxidative stress was already increased in the MDA-MB 231 breast cancer xenograft of mice consuming FOC before the initiation of DOX therapy, thereby increasing the sensitivity of the cancer xenograft to DOX.

The results of this study demonstrate that the implanted MDA-MB 231 tumors of mice that consumed FOC were more sensitive to DOX induced growth suppression and exhibited more oxidative damage than the tumors of mice that consumed the $\mathrm{CO}$ diets. Assay of antioxidant enzyme activity in the tumors, prior to initiation of DOX therapy, found that the GPX activity was already less in mice fed FOC and significantly less in mice fed FOC + vitamin E than in mice fed either CO diet. Reduced GPX activity could be due: 1) to reduced transcription of GPX in the tumor 2) to 'using up' of the antioxidative capacity of GPX or 3 ) to suppression of GPX activity by hydroperoxide products of lipid peroxidation [17]. Further investigation is needed to determine the precise reason but it is evident that GPX activity was not maintained in tumor cells of mice that consumed the FOC.

How could reduced GPX activity, associated with consumption of polyunsaturated fatty acids increase the sensitivity to oxidative stress? GPX has been described as the most important enzyme for stabilizing oxidative reactions in cells [17]. Under normal conditions, inhibition of GPX is sufficient to alter cell survival [17] and low GPX activity is especially lethal under conditions of oxidative stress such as treatment with antineoplastic agents [17]. PUFAs can undergo spontaneous and free radical-initiated chain reactions of lipid peroxidation resulting in the formation of reactive lipid hydroperoxides. Both GPX and CAT can neutralize peroxides but GPX has been reported to be more important than CAT to neutralize lipid hydroperoxides [18]. In cells with a high susceptibility for lipid peroxidation (i.e. tumor cells of FOC fed mice), adequate GPX activity is essential to neutralize lipid hydroperoxides, breaking the chain reaction of peroxidative damage and thus reducing the generation of free radicals. In the current study and in our previous report [15], of the variables measured, the FOC induced decrease in GPX activity in the tumor best explained the increased sensitivity of the tumor to subsequent DOX chemotherapy. GPX was not decreased in the normal colon or liver indicating that normal tissues responded to the FOC diet differently than did the tumor and that normal tissues could maintain GPX activity.

\section{Body weight and tumor growth rate}

It has been reported that omega 3 fatty acids can decrease tumor cachexia [19-21]. It is important to note that tumor bearing mice that received only 3\% FOC in their diet gained more weight prior to initiation of DOX therapy than mice that did not receive FOC. At the initiation of DOX therapy, the tumors of FOC fed mice were slightly, (but not significantly) smaller than the tumors of the $\mathrm{CO}$ fed mice and at the end of the study the tumors of FOC fed mice were significantly smaller than the tumors of $\mathrm{CO}$ fed mice, thus the higher weight gain has to be body weight, not tumor weight. The significantly higher body weight gain is likely due to reduced tumor related cachexia.

$\mathrm{CO}$ and FOC fed groups did not lose different amounts of body weight during DOX treatment. This fact and the maintenance of antioxidant enzyme production in colon and liver are indications that the toxicity of DOX to normal host tissues was not increased by the FOC diet.

The tumor growth curves (Figure 1) illustrate the significant enhancement of the efficacy of DOX against MDAMB 231 human breast cancer xenografts when FOC was incorporated in the diet. The tumor growth rate of mice consuming either FOC diet was significantly less than the tumor growth rate of mice consuming either $\mathrm{CO}$ diet. It is interesting that adding vitamin $\mathrm{E}$ to the $\mathrm{CO}$ diet slightly increased the mean growth rate of the tumors. Since vitamin E quenches oxidation and oxidative damage is one of the mechanisms of action of DOX [13], it would be expected that addition of vitamin $\mathrm{E}$ to the diet of mice bearing tumors with adequate GPX activity, might reduce the efficacy of DOX against the tumor.

\section{Conclusions}

These results indicate that n-3 PUFAs in the diet are incorporated in cell membranes, increasing the polyunsaturation of the membrane and increasing the susceptibility for lipid peroxidation. The inability of cancer cells to maintain the activity of GPX in the presence of a diet containing n-3 PUFAs was related to increased oxidative damage to membrane lipids and to significant enhancement of the efficacy of DOX therapy. Tumor bearing mice that consumed n-3 PUFAs gained more weight prior to DOX therapy than mice that did not receive $n-3$ PUFAs indicating that tumor induced cachexia was reduced. Clinical trials are needed to test the use of this non-toxic supplement as an adjuvant for patients undergoing DOX chemotherapy.

\section{Methods and Materials \\ Preparation of cells}

Cultured MDA-MB 231 cells (American Type Culture Collection, Rockville, MD) were harvested, rinsed then suspended in serum-free M3D base culture medium (INCELL Corporation, LLC, San Antonio, TX). Cells in suspension 
Table 6: The energy content of the diet, calculated at $16.7 \mathrm{~J} / \mathrm{g}$ for protein and carbohydrate, $37.7 \mathrm{~J} / \mathrm{g}$ for fat is $16.3 \mathrm{~J} / \mathrm{g}$. Diet components and chemicals - Purified high nitrogen casein, pure corn starch, Alphacel (non-nutritive bulk cellulose), AIN-76 vitamin mixture, AIN76 mineral mixture and choline bitartrate (99\% pure) was obtained from ICN Nutritional Biochemicals, Cleveland, OH. Imperial brand (Sugarland, TX) extra fine pure cane sugar and 100\% pure corn oil (Wesson) were purchased locally. D.L. methionine was purchased from Sigma, St. Louis, MO. Corn oil (CO) contains about $50 \%$ linoleic acid, $23 \%$ oleic acid, $10 \%$ C I 6 fatty acids and < I\% n-3 PUFAs. The $n-3$ ethyl ester concentrate of fish oil (FOC) contains $>65 \%$ n-3 ethyl esters, ( $>33 \%$ EPA, $>22 \%$ DHA, $10 \%$ other $n-3$ fatty acids), was supplied antioxidant free by Lipromega AS, Norway.

Composition of the diet

$\begin{array}{ll}\text { Ingredient } & \mathrm{g} / \mathrm{l} 00 \mathrm{~g} \\ \text { Total fat } & 5.0 \\ \text { Sugar } & 50.0 \\ \text { Casein } & 20.0 \\ \text { Cornstarch } & 15.0 \\ \text { AIN-76 vitamin mix } & 1.0 \\ \text { AIN-76 mineral mix } & 3.5 \\ \text { Choline bitartrate } & 0.2 \\ \text { DL-methionine } & 0.3 \\ \text { Fiber } & 5.0\end{array}$

were counted using a hemocytometer and the cell count was adjusted to $20 \times 10^{6} / \mathrm{ml}$. The suspension was kept well mixed during the time of injection. MDA-MB 231 cells $\left(1 \times 10^{6}\right.$ cells in $0.05 \mathrm{ml}$ of serum free media) were injected sc between the scapulae of each mouse.

\section{Dietary fatty acids}

Corn oil (CO) contains about 50\% linoleic acid, 23\% oleic acid, 10\% C16 fatty acids and $<1 \%$ n-3 PUFAs. The n-3 ethyl ester concentrate of fish oil (FOC) containing $>$ $65 \% \mathrm{n}-3$ ethyl esters, (> 33\% EPA, > 22\% DHA, 10\% other n-3 fatty acids), was obtained from the Lipro AS, Norway and was supplied antioxidant-free. This oil is made in accordance with Good Manufacturing Practice and is approved as a food additive for humans. The oil is saturated with nitrogen to prevent oxidation during shipping and storage.

\section{Animals and diet}

This experiment was conducted at the University of Texas Health Science Center. All animal use and handling was approved by the UTHSCSA Institutional Animal Care and Use Committee. Eighty female athymic nu/nu mice (Harlan Sprague Dawley Inc. Madison, WI), 3 months old received tumor cells. The mice were housed under aseptic conditions in a temperature $\left(24^{\circ} \mathrm{C}\right)$ and light-controlled (12 h/day) room.

The tumor cell bearing mice were fed the AIN-76 semipurified diet from receipt until three weeks after injection of cells to allow the tumor to become established. Nude mice bearing growing MDA-MB-231 human breast carcinoma xenografts were then divided into four dietary groups (20 mice per group) such that the mean tumor size was not different between groups. One group received the standard AIN-76 diet containing 5\% CO (the CO diet), one group received the 5\% $\mathrm{CO}$ diet supplemented with $2000 \mathrm{IU} / \mathrm{kg}$ Vitamin $\mathrm{E}$ (the $\mathrm{CO}+\mathrm{E}$ diet), one group, received the AIN-76 diet modified to contain 3\% FOC and $2 \% \mathrm{CO}$ (the FOC diet) and the final group received the $3 \%$ FOC and 2\% CO supplemented with $2000 \mathrm{IU} / \mathrm{kg} \mathrm{Vi-}$ tamin $\mathrm{E}$ (the FOC+E diet). Supplemental vitamin $\mathrm{E}$ was added to quench in vivo lipid peroxidation due to the diet. The diet composition is given in Table 6. Diets were prepared weekly, daily portions were individually packaged and stored at $-20^{\circ} \mathrm{C}$ in sealed containers with nitrogen gas atmosphere to prevent lipid peroxidation. Mice were fed fresh food each day and food remaining in the cage was discarded.

\section{Tumor and body weight measurements}

Lengths and widths of tumors and body weights were measured three times weekly. Tumor sizes were calculated using the formula for the volume of a prolate spheroid: $\mathrm{V}$ $=4 / 3 * 3.14 * \mathrm{~L} / 2 * \mathrm{~W} / 2 * \mathrm{D} / 2$. The width measurement was used as the depth of the tumor. The body weight change before DOX treatment was determined by subtracting the mouse body weight on the day of the diet change from the body weight on the day of the first DOX treatment, thus this represents body weight change due to effects of the growing tumor and of the diet. The body weight change after DOX treatment was determined by subtracting the mouse body weight on the day of the first DOX injection from the mouse body weight on the day of killing and represents body weight change due to diet, to the growing tumor and to DOX therapy. 


\section{Doxorubicin therapy}

After two weeks of consumption of the diets, five tumor bearing mice from each dietary group were killed for assay of the effects of the diet on the tumor and normal tissues of the mice. DOX therapy ( $5 \mathrm{mg} / \mathrm{kg}$ body weight each 4 days, i.v. in a lateral tail vein) was initiated on the remaining mice of each group. Five tumor bearing mice from each group were killed $24 \mathrm{~h}$ after one dose of DOX for determination of the acute effects of DOX on the sensitized tumors and normal tissues. After two weeks of DOX treatment, mice were losing excess weight at the given schedule of DOX treatment so the spacing of injections was increased to each seven days for the next three weeks and mouse weight stabilized. The remainder of the mice (10 per diet group) received DOX treatment for a total of five weeks to allow time to generate tumor growth curves and to determine the long term effects of FOC consumption and/or DOX treatment. Thus if day 0 was the day of the first injection, mice received DOX injections on days 0,4 , $8,12,19,26$, and 33 and were sacrificed on day 1 or on day 34 .

\section{Necropsy and tissue processing}

Mice were deeply anesthetized using a ketamine/rompun solution prepared by the UTHSCSA veterinarian. The tumor, liver and large intestines were removed at necropsy. Portions of each tissue were placed individually in a labeled vial and flash frozen in liquid nitrogen. At a later date, frozen livers, colon or tumor were thawed and homogenized individually at $4^{\circ} \mathrm{C}$ in $280 \mathrm{mM}$ mannitol with $10 \mathrm{mM}$ HEPES buffer with $0.01 \%$ BHT using a Polytron homogenizer. The homogenate was divided into aliquots and frozen at $-70^{\circ} \mathrm{C}$ until subsequent analyses.

\section{Products of lipid peroxidation in tumor, liver, and colon} The total protein content of an aliquot of each tissue homogenate was analyzed by the method of Bradford [22] using the Bio-Rad protein assay (micro-method). The thiobarbituric acid reactive substances (TBARS) assay was used to estimate lipid peroxidation in the homogenate. Malondialdehyde and other products of lipid peroxidation can be estimated spectrophotometrically at $535 \mathrm{~nm}$ after reaction with thiobarbituric acid to obtain an index for lipid peroxidation [23]. The absorbance values obtained were compared against a standard curve of known concentrations of malondialdehyde and normalized to the protein content of the specimen. The results were reported as nmol of TBARS per mg of protein.

\section{Gas chromatography (GC)}

The incorporation of fatty acids into the mitochondria and microsomes of colon, liver and tumor was determined in mice which consumed each diet. An aliquot of each whole tissue homogenate was fractioned into mitochondrial and microsomal fractions by successive centrif- ugation [ $600 \times \mathrm{g}$ for $10 \mathrm{~min}$ (remove large debris), 15,000 $\times \mathrm{g}$ for $5 \mathrm{~min}$ (mitochondrial fraction), then $100,000 \times \mathrm{g}$ for $1 \mathrm{~h}$ (microsomal fraction)] for assay of lipid composition. Chloroform:methanol was used for lipid extraction of each fraction; lipids were esterified in acetyl chloridemethanol as described [24]. Gas chromatography was done using a Hewlett Packard 5890 Series 11 Gas Chromatograph (Palo Alto, CA) and conditions of: oven@ $170^{\circ} \mathrm{C}$ initial, $5^{\circ} / \mathrm{min}$ gradient to $220^{\circ} \mathrm{C}$ final temperature, injector temperature @ $225^{\circ} \mathrm{C}$, flame-ionization detector @ 250 ${ }^{\circ} \mathrm{C}$, helium carrier gas @ $400 \mathrm{Kpa}$. Fatty acid methyl ester standards (Nu-Chek-Prep, Elysian, MN) were used for peak identification. The fatty acid methyl esters were reported as the percent of the total methylated fatty acids (area under the curve).

\section{Enzyme assays}

Catalase (CAT) activity in the tissue homogenates was assayed using a microplate adaptation of the method of Aebi [25]. In this method, the decomposition of $\mathrm{H}_{2} \mathrm{O}_{2}$ due to CAT activity was assayed by the decrease in the absorbance of $\mathrm{H}_{2} \mathrm{O}_{2}$ at $240 \mathrm{~nm}$.

Superoxide dismutase (SOD) activity of tissue homogenates was determined using a microplate adaptation of the ferricytochrome $\mathrm{C}$ reduction assay of Flohé and Ötting [26]. In this method, the reduction of cytochrome $C$ by superoxide radicals is monitored at $550 \mathrm{~nm}$ utilizing the xanthine-xanthine oxidase system as the source for superoxide.

Glutathione peroxidase (GPX) activity of tissue homogenates was determined using a microplate adaptation of the glutathione peroxidase assay of Paglia and Valentine [27]. This method follows the decrease in absorbance at $340 \mathrm{~nm}$ as NADPH is converted to NADP.

\section{Statistical analyses}

SAS computer software was used for statistical analyses. Tests for normality (basic statistics) were used on each data set. Two-way and one-way analyses of variance (ANOVA) followed by Student-Newman-Keuls (SNK) multiple range tests, as appropriate, were used to determine statistically significant $(\mathrm{p}<0.05)$ differences in measured parameters due to the diet or to the chemotherapy. PRISM ${ }^{\mathrm{TM}}$ (GraphPad Software, San Diego, CA) was used to generate an ANOVA to test for differences between linear regression curves of tumor growth. Multiple linear regression analysis with forward selection was used to test for correlations in the data between the independent variables: SOD, CAT and GPX activity in the tumor prior to DOX therapy, and TBARS prior to or after DOX therapy and the dependent variable, the tumor growth rate following DOX treatment. 


\section{Acknowledgements}

This work was supported by the Susan G. Komen Breast Cancer Foundation and by the American Institute for Cancer Research.

\section{References}

I. Begin ME, Ells G, Das UN, Horrobin DF: Differential killing of human carcinoma cells supplemented with $n-3$ and $n-6$ polyunsaturated fatty acids. J.Natl Cancer Inst. 1986, 77:1053-1062

2. Gonzalez MJ, Schemmel RA, Gray JI, Dugan LJ, Sheffield LG, Welsch CW: Effect of dietary fat on growth of MCF-7 and MDAMB23 I human breast carcinomas in athymic nude mice: Relationship between carcinoma growth and lipid peroxidation product levels. Carcinogenesis 1991, I 2:1231-1235

3. Rose DP, Connolly JM, Rayburn J, Coleman M: Influence of diets containing eicosapentaenoic or docosahexaenoic acid on growth and metastasis of breast cancer cells in nude mice. J Natl Cancer Inst. 1995, 87:587-592

4. Gonzalez MJ, Schemmel RA, Dugan L, Gray JI, Welsch CW: Dietary fish oil inhibits human breast carcinoma growth: a function of increased lipid peroxidation. Lipids 1993, 28:827-832

5. Begin ME, Ells G, Horrobin DF: Polyunsaturated fatty acid-induced cytotoxicity against tumor cells and its relationship to lipid peroxidation. J Natl Cancer Inst. 1988, 80: I88-194

6. Das UN: Tumoricidal action of cis-unsaturated fatty acids and their relationship to free radicals and lipid peroxidation. Cancer Lett 1991, 56:235-243

7. Gonzalez MJ: Fish oil, lipid peroxidation and mammary tumor growth. J Am Coll Nutr. 1995, I4:325-335

8. Hardman WE, Barnes CJ, Knight CW, Cameron IL: Effects of iron supplementation and ET-I 8-OCH $\mathrm{CH}_{3}$ on MDA-MB 23 I breast carcinomas in nude mice consuming a fish oil diet. $\mathrm{Br} J$ Cancer 1997, 76:347-354

9. Hardman WE, Moyer MP, Cameron IL: Dietary fish oil sensitizes A549 lung xenografts to doxorubicin chemotherapy. Cancer Lett 2000, I 5 I: | 45-I5 |

10. Shao Y, Pardini L, Pardini RS: Dietary menhaden oil enhances mitomycin $C$ antitumor activity toward human mammary carcinoma MX-I. Lipids 1995, 30:1035-1045

II. Shao Y, Hull J, Pardini L, Pardini RS: Dietary menhaden oil improves the therapeudic index of cyclophosphamide and 5fluorouracil towards MX-I human mammary carcinoma in athymic mice. Proc Am Assn Cancer Res: 1997, 38: 110

12. Hardman WE, Moyer MP, Cameron IL: Fish oil supplementation enhanced CPT-I I (Irinotecan) efficacy against MCF7 breast carcinoma xenografts and ameliorated intestinal side effects. Br J Cancer 1999, 8 I:440-448

13. Dorr RT, Von Hoff DD: Cancer Chemotherapy Handbook (Edited by: Dorr RT, Von Hoff DD) Connecticut: Appleton \& Lange 1994

14. Vankatraman JT, Chandrasekar B, Kim JD, Fernandes G: Effects of n3 and n-6 fatty acids on the activities and expression of hepatic antioxidant enzymes in autoimmune-prone NZB $\times$ NZW F, mice. Lipids 1994, 29:56|-568

15. Hardman WE, Avula CPR, Fernandes G, Cameron IL: Three percent dietary fish oil concentrate increased efficacy of doxorubicin against MDA-MB 23 I breast cancer xenografts. Clin Cancer Res. 2001, 7:204I-2049

16. Das UN: Tuning free radical metabolism to kill tumor cells selectively with emphasis on the interaction(s) between essential fatty acids, free radicals, lymphokines and prostaglandins. Indian J Pathol Microbiol. 1990, 33:94- II I

17. Remacle J, Lambert D, Raes M, Pigeolet E, Michiels C: Importance of various antioxidant enzymes for cell stability: Confrontation between theoretical and experimental data. Biochem J 1992, 286:41-46

18. Fernandes G, Chandrasekar B, Luan X, Troyer DA: Modulation of antioxidant enzymes and programmed cell death by $n-3$ fatty acids. Lipids 1996, 31 :S91-S96

19. Tisdale MJ, Dhesi JK: Inhibition of weight loss by omega-3 fatty acids in an experimental cachexia model. Cancer Res 1990, 50:5022-5026

20. Tisdale MJ: The effects of eicosapentaenoic acid on tumour growth and cachexia in the MACI6 mouse colon cancer model. In: New approaches to cancer treatment: Unsaturated lipids and photodynamic therapy. (Edited by: Horrobin DF) London: Churchill Livingston 1995, 30-39
21. Wigmore SJ, Ross JA, Falconer JS, Plester CE, Tisdale MJ, Carter DC, Fearon $\mathrm{KCH}$ : The effect of polyunsaturated fatty acids on the progress of cachexia in patients with pancreatic cancer. Nutrition 1996, I 2:S27-S30

22. Bradford MM: $\mathbf{A}$ rapid and sensitive method for the quantitation of microgram quantities of protein utilizing the principle of protein-dye binding. Anal Biochem 1976, 72:248-254

23. Esterbauer $\mathrm{H}$, Zollner $\mathrm{H}$ : Methods for determination of aldehydic lipid peroxidation products. Free Rad Biol Med 1989, 7:197203

24. Ackman RG: Simplification of analyses of fatty acid in fish lipids and related lipid samples. Acta Med Scand 1987, 222:99-103

25. Aebi H: Catalase in vitro. Methods Enzymol 1984, 1 05: I 2 I- I 25

26. Flohe L, Otting F: Superoxide dismutase assays. Methods Enzymol 1984, 105:93-104

27. Paglia DE, Valentine WN: Studies on quantitative and qualitative characterization of erythrocyte glutathione peroxidase. J Lab Clin Med 1967, 70:158-169 